\title{
LA FAUNA FANTÁSTICA EN FRAGMENTOS DE APOCALIPSIS: LA RECONCEPTUALIZACIÓN ESPACIAL DEL DRAGÓN FEO
}

\author{
Alba Rozas Arceo \\ Universidade de Santiago de Compostela
}

\section{RESUMEN}

En el presente trabajo se ofrece una aproximación contrastiva a la conceptualización de la Coca, dragón mitológico popular gallego, como Dragón Feo en la obra Fragmentos de Apocalipsis, autoría de Gonzalo Torrente Ballester, en función de su tratamiento espacial. Con este propósito, se analiza la concepción de dicha criatura mitológica en la tradición gallega y la deconstrucción espacial del dragón llevada a cabo por Torrente en su obra, a partir de la relación entre espacio, experiencia y organización del conocimiento, de acuerdo con las aportaciones de la geografía literaria y las geografías personales de David Lowenthal.

Palabras ClaVE. Coca, dragón, espacio, geografía literaria, geografías personales.

\section{ABSTRACt}

This essay offers a comparative approach to the conceptualization of the Coca, a Galician popular mythological dragon, as a Dragón Feo in the book Fragmentos de Apocalipsis by Gonzalo Torrente Ballester, focusing on its spatial treatment. With this goal, it analyzes the conception of the mythical creature in Galician tradition and the spatial deconstruction of the dragon that Torrente does in his book, working from the relationship between space, experience and organization of knowledge, following the principles of literary geogprahy and personal geographies established by David Lowenthal.

KEY WORDS: Coca, dragon, space, literary geography, personal geographies.

\section{INTRODUCCIÓN: LA COCA Y EL MITO DEL DRAGÓN}

El presente estudio pretende ofrecer un análisis de la conceptualización de 
la Coca, animal fantástico de la mitología popular gallega, como Dragón Feo, en la obra Fragmentos de Apocalipsis de Gonzalo Torrente Ballester. Con este propósito, presentamos, en primer lugar, una aproximación a la concepción tradicional de este ser mitológico.

En su estudio «A coca e o dragón: Introducción á zooloxía fantástica» Xosé Ramón Mariño Ferro analiza lo que él denomina «unha das creacións humanas máis enigmáticas: o dragón» ${ }^{1}$. De acuerdo con este antropólogo, el dragón aparece en muchas leyendas, en cuentos, imágenes y procesiones de Galicia y de gran parte de Europa a lo largo de bastantes siglos. En las ciudades de Redondela, Pontevedra y otras villas gallegas llaman «Coca» a la figura de un monstruo que forma parte de la procesión del Corpus Christi y que con el mismo nombre se conoce en Monçao, Portugal. También se sabe que en Francia gozaron de gran popularidad estas imágenes, destacando especialmente la de Tarascón ${ }^{2}$.

Un simple vistazo a estas, figuras, también denominadas tarascas ${ }^{3}$, permite constatar que la Coca es un dragón y así aparece identificado en la propia leyenda redondelana:

[...] un animal extraño y monstruoso, con cuerpo de dragón terminado en una enorme cola como de gran serpiente, con enormes alas semejantes a las de un murciélago colosal, fuertes garras en sus cuatro fornidas patas y una cabeza en la cual relucían como ascuas unos ojos terribles, abriéndose en la parte interior una boca de mandíbulas enormes armadas de fuertes y aguzados dientes ${ }^{4}$.

Para logar una correcta interpretación de este animal y sus características físicas, como su aspecto de serpiente, sus alas y el fuego, es necesario sumergirse en la filosofía medieval $^{5}$.

En su estudio sobre las tarascas, Mariño explica que en algunas iglesias, particularmente en las Galias, es costumbre llevar en las procesiones de letanías menores - tres días antes de conmemorar la ascensión de Cristo-, la imagen de un dragón con una enorme cola rellena de paja. Durante las procesiones de los primeros días esta imagen con la cola hinchada y levantada antecede a la cruz, pero al tercer día, se sitúa detrás de la cruz con el rabo bajo y vacío. Esto pretende representar que el demonio reinó en el mundo durante el tiempo anterior a la promulgación de la

\footnotetext{
${ }^{1}$ Mariño Ferro, X. R., «A coca e o dragón: Introducción á zooloxía fantástica», en Actas do I Congreso Internacional da Cultura Galega, Santiago de Compostela, Dirección Xeral de Cultura, 1992, p. 289.

${ }^{2}$ Mariño Ferro, X. R., «A coca e o dragón: [...]», art. cit., p. 289.

${ }^{3}$ Este nombre deriva de la fama alcanzada por dichas efigies en la población francesa de Tarascón.

${ }^{4}$ Carré Alvarellos, L., Las leyendas tradicionales gallegas, Madrid, Espasa-Calpe, 2004, p. 175.

${ }^{5}$ Mariño Ferro, X. R., «A coca e o dragón: [...]», art. cit., p. 289. 
ley - el primer día de plegarias - y en la época en la que el pueblo judío vivió bajo la ley antigua - el segundo día de plegarias - pero perdió su imperio con la Pasión de Cristo, que dio paso al tiempo de gracia - el tercer día de plegarias ${ }^{6}$.

El propio evangelista San Juan en el Apocalipsis nos aclara que por dragón debemos entender «la serpiente antigua, el llamado Diablo y Satanás» ${ }^{7}$, la cual se presenta como un «gran dragón rojo, que tenía siete cabezas, diez cuernos y una corona en cada cabeza», criatura que "arrastró con la cola a la tercera parte de las estrellas del cielo, y las arrojó a la tierra» ${ }^{8}$.

El Bestiario de Cambridge, escrito en el siglo XII, ofrece una simbología más detallada:

El demonio, que es el más enorme de todos los reptiles, es como este dragón. A menudo sale de su guarida lanzándose al espacio, y el aire en torno a él se inflama, pues [...] al elevarse de las regiones inferiores, se convierte en un ángel de la luz y engaña a los necios con falsas esperanzas de gloria y de goce terrenal. Se dice que tiene una cresta o corona, porque es el Rey de la Soberbia, y su fuerza no está en los dientes sino en la cola, porque engaña a los que atrae hacia él con artimañas, destruyendo su fortaleza9.

Son los santos militares, de acuerdo con su profesión, los que se enfrentan al dragón con armas. San Jorge es el caballero cristiano por excelencia, patrón de Inglaterra, de Portugal, de Cataluña, de Génova y de la caballería en general, que como caballero decidirá enfrentarse al dragón para salvar a una doncella ${ }^{10}$. Según la compilación de relatos hagiográficos reunida por el dominico Jacobo de la Vorágine - arzobispo de Génova - a mediados del siglo XIII, La leyenda dorada ${ }^{11}$, había un dragón monstruoso que habitaba un lago cerca de Silca, en la provincia de Libia. Para saciar el apetito del monstruo, los habitantes de la ciudad ponían diariamente a su alcance dos ovejas, pero las reses se terminaron y hubo que ofrecer personas. Cuando debía morir la hija del rey y, a pesar de que su padre, consternado, ofreció sus tesoros a cambio de la vida de la muchacha, el pueblo la reclamó. La doncella, tras ser conducida al lago, fue abandonada cerca de la guarida del dragón. Entonces, pasó el caballero Jorge y, al descubrir lo que acontecía, decidió enfrentarse al dragón, lo hirió con su lanza, le dijo a la joven que atase con su cinturón a la bestia herida y esta siguió a la muchacha como un perrillo faldero. Cuando llegó a la puerta de la muralla de la ciudad, la gente

\footnotetext{
${ }^{6}$ Mariño Ferro, X. R., «A coca e o dragón: [...]», art. cit., pp. 289-90.

${ }^{7}$ Ap., 12, 9.

${ }^{8}$ Ap., 3-4.

${ }^{9}$ Malaxecheverria, I., Bestiario medieval, Madrid, Siruela, 1999, p. 181.

${ }^{10}$ Mariño Ferro, X. R., «A coca e o dragón: [...]», art. cit., p. 290.

${ }^{11}$ Vorágine, J., La leyenda dorada, Madrid, Alianza, 1982, p. 250.
} 
se asustó y quiso huir. San Jorge trató de detenerlos y tranquilizarlos:

¡No tengáis miedo! [...] Dios me ha traído hasta esta ciudad para libraros de este monstruo. ¡Creed en Cristo y bautizaos! ¡Ya veréis como yo mato a esta bestia en cuanto todos hayáis recibido el bautismo! Rey y pueblo se convirtieron y, cuando todos los habitantes de la ciudad hubieron recibido el bautismo, san Jorge, en presencia de la multitud, desenvainó su espada y con ella dio muerte al dragón ${ }^{12}$.

Para entender el triunfo sobre el dragón por medio del bautismo hay que tener en cuenta que, en la Edad Media, el paganismo constituía el imperio de Satanás y bajo las imágenes de los dioses paganos se hallaba el demonio, como queda señalado en $\mathrm{La}$ leyenda dorada. En otras palabras, la tradición cristiana hizo del dragón un símbolo del paganismo y del diablo ${ }^{13}$.

En primer lugar, es necesario destacar que el dragón es una serpiente. Como señala Mariño «os gregos denominaban drakon e os latinos draco a toda serpe de gran tamaño» ${ }^{14}$. San Isidoro se refiere al dragón en el capítulo de las Etimologías dedicado a las serpientes:

El dragón es la mayor de todas las serpientes, e incluso de todos los animales que habitan en la tierra [...] su fuerza no radica en los dientes, sino en la cola, y produce más daño cuando la emplea a modo de látigo que cuando se sirve de su boca para morder. Es inofensivo en cuanto al veneno, puesto que no tiene necesidad de él para provocar la muerte: mata siempre asfixiando a su víctima ${ }^{15}$.

De acuerdo con el antropólogo, esa serpiente «parece inspirada na pitón, grande, non venenosa e que mata por asfixia» ${ }^{16}$. Pero el dragón de las leyendas del medievo no es una simple serpiente, pues está constituido, además, por miembros de otros animales que no fueron elegidos al azar. En el caso del dragón «foron seleccionados os animais especialmente agresivos e perigosos e, destes, os membros destinados a causar a morte: as fauces do crocodilo, a súa cola ou a da pitón, as poutas da aguia ou do león, etc.» ${ }^{17}$.

Los animales escogidos constituyen el símbolo de los tres medios naturales que se corresponden con tres de los cuatro elementos de la filosofía antigua: tierra, agua y aire. De hecho, como apunta Mariño «era común que nas representacións artísticas o león ou a serpe servisen de atributo ó elemento Terra; o crocodilo, á auga; a aguia,

\footnotetext{
${ }^{12}$ Vorágine, J., La leyenda dorada, ob. cit., p. 250.

${ }^{13}$ Mariño Ferro, X. R., «A coca e o dragón: [...]», art. cit., p. 291.

${ }^{14}$ Mariño Ferro, X. R., «A coca e o dragón: [...]», art. cit., p. 291.

${ }^{15}$ San Isidoro, Etimologías, Madrid, Biblioteca de autores cristianos, 2000, XII, 4, 4-5.

${ }^{16}$ Mariño Ferro, X. R., «A coca e o dragón: [...]», art. cit., p. 291.

${ }^{17}$ Mariño Ferro, X. R., «A coca e o dragón: [...]», art. cit., p. 291.
} 
La fauna fantástica en Fragmentos del Apocalipsis: la reconceptualización espacial del dragón feo

ó aire» ${ }^{18}$. Tampoco falta el fuego que el dragón escupe por la boca. Este elemento está tomado, en consonancia con los demás, en su aspecto destructivo, no purificador. Así, el dragón constituye un animal artificial de cariz aéreo, acuático, terrestre e ignífero, construido a partir de las armas más letales de la naturaleza. En otras palabras, el dragón es «a representación do Animal Maléfico ou, se se prefire, da Maldade Animal [...] a Faceta Maléfica da Naturaleza», motivo suficiente para servir de cuerpo al espíritu del mal y pervivir hasta nuestros días ${ }^{19}$.

\section{La fauna fantástica de Fragmentos de Apocalipsis: el Dragón Feo.}

La concepción de este ser fantástico elaborada por Torrente Ballester en Fragmentos de Apocalipsis es bien distinta. El autor representa al Dragón Feo, a partir de la concepción bíblica y medieval de esta criatura, como un dechado de fealdad, con una dimensión musical e irrisoria:

Los siete pares de cuernos [...] se aproximaban lentamente: como una escuadrilla de submarinos que sacase al sobrehaz los periscopios [...]. De pronto, se sumergieron los cuernos, y allá lejos, remotos, se oyeron los coletazos que sacudían el agua: un cuerpo largo fue emergiendo, horrendamente escamoso, entre boa de constrictor y de caimán, pero con alas atrofiadas como de piedra; venía después un tórax jorobado, y el arranque de siete pescuezos delgaditos, ridículos en proporción al cuerpo [...] asomaba una de las cabezas, algo así como de un perro que fuese al mismo tiempo loro y un poco de lagarto. Me miraba con tristeza [...] su voz dulcísima en fa menor [...]. La cabeza en sol apareció también, como explorando [...]. La cabeza en do emergió también, y tras ella, las que quedaban ocultas: todas humildes y feas, con largas lenguas bífidas y dientes amarillos: diferentes, y en todas se cumplía la mescolanza de parecidos, si bien intercambiados y turnantes los animales de referencia, pues la cabeza en fa menor se parecía ahora a un mico que fuese al mismo tiempo halcón y pescadilla, y por los rostros de las demás andaban toda clase de simios, los gallináceos, parrulos y otras aves de corral, las tencas, besugos, jureles y tres o cuatro variedades de salmónidos, las aves de rapiña, murciélagos, cotorras, ruiseñores, felinos de poca monta, sabandijas, comadrejas, ratones y cucarachas: especies todas dotadas de natural belleza, mírese como se mire, pero que, mezcladas como allí aparecían quedaban feas ${ }^{20}$.

Sin embargo, el propio autor define al Dragón Feo como un ser inofensivo y bienhechor:

El Dragón Feo [...] es la criatura menos temible del mundo. No sólo es apacible, sino también benévolo, e incluso benefactor. Cuando soplan las galernas y los barcos no pueden salir del puerto, el dragón abandona su escondite, se hace a la mar y trae a la otra orilla la pesca necesaria para que el pueblo coma. También ahuyenta a los arroaces que destruyen las artes, y a los grandes tiburones cuando

\footnotetext{
${ }^{18}$ Mariño Ferro, X. R., «A coca e o dragón: [...]», art. cit., p. 292.

${ }^{19}$ Mariño Ferro, X. R., «A coca e o dragón: [...]», art. cit., p. 291.

${ }^{20}$ Torrente Ballester, G., Fragmentos de Apocalipsis, Barcelona, Destinolibro, 1982, pp. 122-23.
} 
los niños se bañan en las orillas ${ }^{21}$.

De hecho, el dragón torrentino expresa sus propios sentimientos afectuosos respecto a la compañera sentimental del protagonista: " "es una muchacha muy hermosa", dijo, "me gustaría hacer algo por ella, como salvarla de un naufragio o enseñarle a nadar" ${ }^{22}$.

Como podemos comprobar, el Dragón Feo se opone a la concepción religiosa del dragón cristiano-medieval y el propio autor manifiesta expresamente su intención de subvertir esta invención humana:

«En los dragones [...] simbolizaron los hombres la maldad de las fuerzas telúricas». «Por eso atormentaron mi niñez, que no podía explicarse por qué devoraban a los hombres, destruían sus ciudades y se portaban mal con las muchachas bonitas. Yo, naturalmente, estaba entonces de parte de San Jorge, y aplaudía que su lanza se hundiese en la garganta flamígera del bicho. Pero, más tarde, comprendí que era injusto, y, para redimir a los dragones, inventé este. Los del pueblo cuentan que hace bastantes siglos, cuando San Jorge andaba por el mundo rematando dragones, llegó a la isla en una barca con velas de púrpura a matar al Dragón Feo, que era el último que quedaba; pero la gente no le dejó desembarcar, y el santo matadragones tuvo que marchar por donde había venido ${ }^{23}$.

Esta representación idiosincrática del dragón se fundamenta en el espacio fantástico en el que se sitúa la criatura: «la isla de Mazaricos, una especie de peñón basáltico perdido en el mar de Occidente, del que emergía como un cetáceo aboyado» ${ }^{24}$. En este lugar, explica Torrente que «no había más que una ciudad, y [...] sus habitantes se dividían en [...] dos bandos, que más parecían razas», aquellas personas que solo se ven de frente y viven «en la parte diestra del pueblo» y las que únicamente se ven de lado y «viven en la siniestra» ${ }^{25}$. Este espacio mítico, favorece la concepción del Dragón Feo como ser mitológico desprovisto de connotaciones maléficas religiosas. De hecho, el autor contrapone esta visión del dragón a la de la Coca medieval cuando sugiere a la criatura trasladarse a Villasanta de la Estrella, explicando a sus siete cabezas que

en ese pueblo hay una Coca que se parece a vosotras. La sacan en algunas procesiones. Si lo queréis, podéis sustituirla, sin otra condición que la de que aprendáis a moveros como se mueve ella: un modo bastante arcaico, por cierto ${ }^{26}$.

Como podemos comprobar, la representación espacial elaborada por el

\footnotetext{
${ }^{21}$ Torrente Ballester, G., Fragmentos de Apocalipsis, ob. cit., p. 121.

${ }^{22}$ Torrente Ballester, G., Fragmentos de Apocalipsis, ob. cit., p. 123.

${ }^{23}$ Torrente Ballester, G., Fragmentos de Apocalipsis, ob. cit., p. 122.

${ }^{24}$ Torrente Ballester, G., Fragmentos de Apocalipsis, ob. cit., p. 105.

${ }^{25}$ Torrente Ballester, G., Fragmentos de Apocalipsis, ob. cit., p. 106.

${ }^{26}$ Torrente Ballester, G., Fragmentos de Apocalipsis, ob. cit., p. 124.
} 
autor favorece, respecto a la criatura mitológica, la subversión de los «elementos interpretativos que tienen su origen en los modelos gnoseológicos generales y en su desarrollo histórico endocéntrico» ${ }^{27}$. La geografía fantástica de la isla de Mazaricos constituye, en el imaginario literario, una población a imitación de la realidad, que se reproduce alterada en la ficción.

Desde la perspectiva de estudio de la geografía literaria, considerando la incorporación de los imaginarios, pueden hallarse los fundamentos subyacentes a la creación de este espacio que sirve de guarida al animal fantástico para analizar el desarrollo de la manifestación sociocultural, artística y literaria del Dragón Feo a partir de la definición de su entorno. La construcción de este imaginario espacial se remonta a las historias «que provee el pensamiento mítico una vez fosilizado y eufemizado» ${ }^{28}$, es decir, adaptado a los sucesivos modelos culturales de representación de acuerdo con la disposición teológica armónica en la que se fundamentan. De esta forma, se genera un lugar idóneo sin localización conocida para ubicar la producción opuesta al orden regular que constituye el Dragón Feo. Esta criatura se presenta en un espacio que «reemplazan con nuevos símbolos los viejos significados de las creencias mitológicas que son a veces refugio de la ontología heterodoxa de quienes rechazan la imperfección social de nuestro mundo» ${ }^{29}$. La continuidad histórica entre la configuración de este espacio, refugio del dragón torrentino, y las formas mitológicas puede percibirse en las rupturas cronológicas y topológicas, pues ambos imaginarios agrupan las representaciones que el ser humano construye del mundo que los rodea y aquellas que surgen como proyección del inconsciente, capaces de inducir actuaciones que vuelvan a modelar la realidad ${ }^{30}$. La historia del mito se desarrolla en un marco conocido y un rasgo fundamental es el tiempo ${ }^{31}$, pues el mito cumple una función legitimadora en la sociedad, por este motivo se sitúa al margen de cualquier concreción histórica, en un «tiempo primordial o tiempo mítico» ${ }^{32}$, y su fuerza de convicción procede de la manera en que se relata, como una palabra del pasado ${ }^{33}$. Así, uno de los habitantes de la isla torrentina reconoce que «los hombres nos han abandonado hace ya siglos, o

\footnotetext{
${ }^{27}$ Querol, J.M., «Imago mundi: la construcción literaria de la geografía mítica, fantástica y política», en T. López Pellisa y Á. Moreno Serrano (eds.), Ensayos sobre ciencia ficción y literatura fantástica, Madrid, Asociación Cultural Xatafi y Universidad Carlos III de Madrid, 2009, p. 863.

${ }^{28}$ Querol, J.M., «Imago mundi: [...]», art. cit., p. 864.

${ }^{29}$ Querol, J.M., «Imago mundi: [...]», art. cit., p. 864.

${ }^{30}$ Claval, P., «Mitos e imaginarios en geografía», en A. Lindón y D. Hiernaux (dirs.), Geografías de lo imaginario, Barcelona, Anthropos, 2012, p. 30.

${ }^{31}$ Claval, P., «Mitos e imaginarios en geografía», art. cit., p. 34.

${ }^{32}$ Rómar, A., «El mito y la ciencia ficción: polos de la explicación imaginaria de la realidad», en T. López Pellisa y Á. Moreno Serrano (eds.), Ensayos sobre ciencia ficción y literatura fantástica, Madrid, Asociación Cultural Xatafi y Universidad Carlos III de Madrid, 2009, pp. 816-19.
}

${ }^{33}$ Claval, P., «Mitos e imaginarios en geografía», art. cit., pp. 36-37. 
quizás nos hayan olvidado ${ }^{34}$. En la misma línea, los relatos míticos se ubican en otro espacio, animado por las fuerzas que modelan los seres y el mundo, el espacio de los orígenes, que se perpetúa en los espacios sagrados donde se refugiaron los poderes que lo caracterizaban. De este modo,

la primera manifestación espacial del imaginario, en la forma que le da el mito, se basa en la oposición absoluta entre dos categorías de lugares, aquéllos transformados por la existencia de poderosas fuerzas y aquellos que permanecen en la banalidad simple de lo profano ${ }^{35}$.

En consecuencia, el descentramiento que conlleva el espacio imaginario torrentino, al igual que el espacio mítico, permite al individuo y a los grupos sociales juzgar al Dragón Feo, orientar su acción y sustraerse de su propia contemporaneidad, respecto a la concepción religiosa medieval de esta criatura mitológica.

Esta funcionalidad del espacio mítico ha constituido siempre uno de los usos más relevantes de la imaginación geográfica. La primera manifestación de dicha tendencia es el mito de la Atlántida, una sociedad ideal basada en el folklore y la mitología, reelaborados como material pseudohistórico por Platón en el Crítias y en el Timeo. Si bien en la primera obra el filósofo griego narra la leyenda de la Atlántida, en la segunda alude a ella en el debate sobre la sociedad ideal, pues la Atlántida representa los valores de la justicia, la virtud y, particularmente, una moral, ya que el Timeo finaliza con la explicación inacabada del castigo divino de los atlantes por su soberbia $^{36}$.

En el Renacimiento, la Atlántida se convirtió en alegato utópico humanista, a la vez que se poblaba de elementos esotéricos y heterodoxos, de hecho, en el siglo XIX tiene lugar la actualización del relato a través del esoterismo tardorromántico en comunión con el nacionalismo ${ }^{37}$.

En Fragmentos de Apocalipsis, Torrente establece un claro paralelismo entre la isla de Mazaricos y la Atlántida al revelar al Dragón Feo que «Está anunciado un cataclismo marítimo que hundirá la isla en el fondo del mar. En su lugar quedará un remolino» ${ }^{38}$.

Del mismo modo, este hecho supone una reconceptualización del mito, ya que el cataclismo no se presenta como un castigo sino como un simple fenómeno natural

\footnotetext{
${ }^{34}$ Torrente Ballester, G., Fragmentos de Apocalipsis, ob. cit., p. 107.

${ }^{35}$ Claval, P., «Mitos e imaginarios en geografía», art. cit., p. 39.

${ }^{36}$ Querol, J.M., «Imago mundi: [...]», art. cit., p. 868.

${ }^{37}$ Querol, J.M., «Imago mundi: [...]», art. cit., p. 869.

${ }^{38}$ Torrente Ballester, G., Fragmentos de Apocalipsis, ob. cit., p. 125.
} 
de modo que, respecto a la gente que la habita, «se está pensando en evacuarla a una isla como ésta, pero la isla no la han encontrado todavía» ${ }^{39}$. De esta forma, el autor proyecta las contradicciones de la modernidad en torno a la concepción de la criatura mitológica del dragón, pues, tal como explica el protagonista de Fragmenos de Apocalipsis, su concepción de dicha criatura como dócil y benévola responde al propósito de negar los valores del cristianismo medieval, impuestos tradicionalmente a la figura del dragón: «en los dragones [...] simbolizaron los hombres la maldad de las fuerzas telúricas [...] más tarde, comprendí que era injusto, y, para redimir a los dragones, inventé este» ${ }^{40}$.

Esta subversión entronca con su proyecto de constituir una modernidad regionalista particular ${ }^{41}$, pues implica una reconfiguración de las tarascas gallegas en una alteridad imaginaria situada frente a la costa de Muxía. De este modo, el autor rompe con la configuración tradicional de estas leyendas y define el dragón y la isla en función de su procedencia geográfica, parodiando los postulados del romanticismo sobre la concepción de la naturaleza (Mazaricos), la vida (el Dragón Feo) y el hombre (los isleños), cuya idiosincrasia resulta verosímil en virtud del espacio fantástico donde se sitúan. Esta concepción de los mitos evidencia la distinción entre la última manifestación del modernismo, que incide en la autosuficiencia de la obra literaria y el postmodernismo, que aborda el tema de la historia como construcción humana ${ }^{42}$. Esta concepción de la historia fundamenta la reconsideración y reutilización del mito del dragón y la Atlántida en la obra de Torrente con la finalidad de reflexionar sobre

la naturaleza problemática de la relación entre la escritura de la historia y la narrativización, cuestionando, por lo tanto, la reivindicación de verdad de la historia, la cual, al igual que la ficción, constituye un discurso, una construcción humana, un sistema de significados ${ }^{43}$.

En este sentido, es posible apreciar en la obra analizada cómo la necesidad de construir la ciencia como fundamento de un nuevo orden social unitario (de acuerdo con el positivismo de Comte) y el final de los espacios en blanco en los mapas provocan una reacción antimaterialista, procedente de la recusación del fin de las expectativas románticas y de la perspectiva orientalista - esto es, de acuerdo con Edward Said, la voluntad intelectual de controlar, manipular e incluso incorporar, aquello que

\footnotetext{
${ }^{39}$ Torrente Ballester, G., Fragmentos de Apocalipsis, ob. cit., p. 125.

${ }^{40}$ Torrente Ballester, G., Fragmentos de Apocalipsis, ob. cit., p. 122.

${ }^{41}$ Nagel, F., «Galicia en movimiento. Topologías mitográficas en la narrativa de Gonzalo Torrente Ballester», en C. Rivero Iglesias (ed.), El realismo en Gonzalo Torrente Ballester: poder, religión y mito, Madrid, Iberoamericana, 2013, p. 276.

${ }^{42}$ Hutcheon, L., Narcissistic Narrative. The Metafictional Paradox, New York, Methuen, 1984, p. 5.

${ }^{43}$ Loureiro, Á., «Torrente Ballester, novelista postmoderno», en Á. Abuín, C. Becerra y M. Candelas (eds.), La creación literaria de Gonzalo Torrente Ballester, Vigo, Tambre crítica, 1997, p. 63.
} 
constituye un mundo manifiestamente diferente ${ }^{44}-$, derivada del desarrollo colonial durante el siglo XIX Así, reaparecen en Europa nuevas formas de enfrentarse a la realidad con espacios en los que el individuo postromántico, «presionado y envilecido por los medios de producción, aniquilado por los sistemas totalitarios», pueda refugiarse «como miembro de un grupo escogido para conocer [...] un orden alternativo en la Historia ${ }^{45}$.

Las aportaciones de David Lowenthal en su artículo de 1997 «Geografía, experiencia e imaginación», basadas en la preponderancia de la sensibilidad y en el análisis de las valoraciones y preferencias que los sujetos desarrollan frente al medio, sirven para poner de manifiesto la reconceptualización espacial del monstruo llevada a cabo por Torrente. Lowenthal reconoce que el conocimiento geográfico se constituye a partir de la relación entre realidad y percepción, que abarca desde el contacto sensible, la experiencia y la organización del conocimiento a través de imágenes, hasta las actitudes y decisiones que definen la intervención de los individuos en el medio. Lowenthal explora las «geografías personales», es decir,

la visión personal del mundo mezclada con la fantasía y el carácter egocéntrico de la experiencia, así como la influencia de la estructura social, el contexto cultural y el lenguaje en la formación de determinadas pautas básicas colectivas ${ }^{46}$.

De acuerdo con Lowenthal, la antropología cultural, la psicología filosófica y la lingüística ofrecen avances teóricos para entender tanto cosmovisiones individuales como grupales, esto es, ligadas a la estructura social, al contexto cultural y al lenguaje. Estas geografías personales conviven con las desarrolladas en distintos momentos históricos y con otras diferenciadas desde el punto de vista cultural ${ }^{47}$.

La representación idiosincrática del Dragón Feo de Torrente Ballester, fruto de su fantasía, implica la subversión de la concepción fantástica del dragón de acuerdo con su experiencia, esto es, con la influencia socio-cultural en la formación de las convenciones colectivas sobre la criatura especificadas anteriormente, las cuales fueron desarrolladas por la comunidad gallega como parte de su tradición histórica, cultural y religiosa. Como el propio autor reconoce en una entrevista:

Ahí ha funcionado la figura de las tarascas. Estos son unos dragones mecánicos que figuran en las procesiones de algunos pueblos, por ejemplo en el norte de

\footnotetext{
${ }^{44}$ Said, E., Orientalismo: o Oriente como invenção do Ocidente, San Pablo, Companhia das letras, 1990, p. 24.

${ }^{45}$ Querol, J.M., «Imago mundi: [...]», art. cit., p. 870.

${ }^{46}$ Capel, H., «Percepción del medio y comportamiento geográfico», Revista de Geografía, 7/1-2 (1973), p. 59.

${ }^{47}$ Zusman, P., «La geografía histórica, la imaginación y los imaginarios geográficos», Revista de Geografía Norte Grande, 54 (2013), pp. 53-54.
} 
Portugal y creo que en el sur de Francia también. Concretamente hay una en Redondela [...] que se llama la Coca, que es un Dragón de una sola cabeza, que va abriendo la boca, y los niños le tiran caramelos. Este dragón de Redondela según la leyenda, representa a un bicho que fue vencido por un personaje mítico y legendario [...]. A mí esto me lo contó un chico de COU en el Instituto de Vigo y yo lo que hice fue transformar el dragón de una sola cabeza en el dragón tradicional de siete cabezas [...] una inversión del mito terrestre que es el dragón que significa lo malo, es decir, hacerlo bueno [...] el dragón es una figura [...] que simboliza el mito [...] una explicación a unos hechos inexplicables. Un hecho inexplicable es el mal, entonces se explica mediante figuras e historias. Estas figuras no son figuras aisladas generalmente, sino que son historias breves, por ejemplo, el caballero que mata al dragón y libera a la doncella. [...], en este caso, [...] dejo simplemente la relación entre el caballero que mata al dragón, al mal. En nuestra civilización éste es San Jorge; como el Dragón es bueno, no toca ningún pito; entonces la gente de la isla dice "usted váyase, que nuestro dragón no nos lo mata usted". O sea, que crea una paradoja sobre una historia: transformar, aplicándole la ironía y la lógica, el sentido del mito [...] yo lo considero versión paradójica de un mito. Utilización paradójica de los elementos del mito; porque ahí no hay destrucción del mito, sino utilización del mito en sentido inverso al que posee ${ }^{48}$.

El vínculo que entabla Torrente con el imaginario fantástico medieval difiere del establecido por los integrantes de la sociedad de la época y que se recrea aún en la actualidad. En la aproximación al pasado llevada a cabo por Torrente, la imaginación es una facultad a partir de la cual se puede otorgar nuevo sentido a las concepciones pretéritas sobre el dragón preservadas hoy en día, aunque permeadas por las visiones del presente. La imaginación se presenta entonces como un mecanismo metodológico que sirve al autor para recrear y revertir en su obra las percepciones heredadas del cristianismo y la época medieval. Además, según el propio autor reconoce, los testimonios orales facilitan esta tarea. En este sentido, la recreación del Dragón Feo, al quedar despojada de dichas valoraciones, pone de relieve todos los rasgos de la criatura como artificio crítico que propicia la desmitificación de su propia historia y la de su entorno. De este modo, tanto la recreación del dragón como de la isla, sirven para poner de manifiesto la entidad estrictamente literaria - fruto de la facultad imaginativa del escritor - de los mitos en su origen. Este procedimiento responde a la finalidad última de

convencer al lector de la imposibilidad de distinguir entre la realidad y la ilusión en los textos históricos. Sin ir completamente en serio, logra dejar claro por qué ha sostenido que el escepticismo es el único refugio del hombre inteligente en nuestro tiempo, y la parodia la única actitud lógica, desmitificando hasta el concepto de cualquier verdad oficial ${ }^{49}$.

\footnotetext{
${ }^{48}$ Becerra, C., Guardo la voz, cedo la palabra, Barcelona, Editorial Anthropos, 1990, pp. 59-60.

${ }^{49}$ Pérez, J., «La función desmitificadora de los mitos en la obra literaria de Gonzalo Torrente Ballester», Actas del octavo Congreso de la Asociación Internacional de Hispanistas: celebrado en Brown University, Providence Rhode Island, del 22 al 27 de agosto de 1983, Volumen II, Madrid, Ediciones Istmo, 1986, p. 446.
} 
Así, pueden comprenderse las actitudes diferenciadas entre la sociedad representada por los habitantes de la isla y San Jorge, en relación a la valorización de la monstruosa criatura.

\section{Conclusión}

Las geografías imaginarias soportan relaciones de poder y conocimiento que descubren reminiscencias respecto a la realidad social a partir de los imaginarios que se articulan a la vida humana, los cuales, transmitidos a través de los relatos, representan la alteridad respecto al mundo real. En este sentido, si tenemos en cuenta que la construcción del espacio fantástico torrentino se remonta al pensamiento mítico, es necesario destacar que su concepción particular del dragón forma parte de la actitud del hombre hacia el pasado y constituye una fórmula para interpretar los fenómenos de invención de los individuos que se manifiestan diariamente ${ }^{50}$. De hecho, esta reformulación de las leyendas del dragón y de la Atlántida implica, en realidad, la desmitificación de ambas historias, pues, gracias a la potencialidad creativa de la palabra, se sitúan en la obra al mismo nivel que el resto de la ficción novelesca. Este procedimiento «forma parte de un proceso más amplio de desmitificación de la ciencia histórica» llevado a cabo por Torrente cuya finalidad es «atacar una interpretación manipulada de la Historia que falsea la verdad» ${ }^{51}$.

La producción fantástica de Torrente, herencia y futuro de las tradiciones medievales, constituye una «anomalía temporal» que va a integrar, al igual que el mito, «los temores y esperanzas del ser humano» ${ }^{52}$. Así, el autor recurre al espacio fantástico que «permite la recreación de la realidad, abre universos para comprender aquel en el que vivimos» $\mathrm{y}$ «proporciona una lección moral, ética y hasta estética en el proceso de transmisión de la concepción histórica del dragón». De este modo, la fantasía «se instituye como un baluarte de franqueza ante la hipocresía de la sociedad», a través del cual se observa la realidad ${ }^{53}$.

En definitiva, mediante las cronologías y topologías desarrolladas en este espacio fantástico de la novela es posible enjuiciar la historia respecto a la concepción del dragón partiendo de que «la construcción de lo social siempre ha ido ligada a la

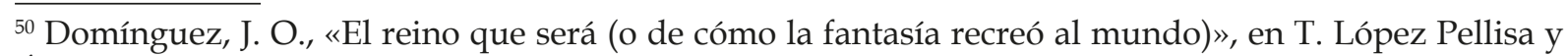
Á. Moreno Serrano (eds.), Ensayos sobre ciencia ficción y literatura fantástica, Madrid, Asociación Cultural Xatafi y Universidad Carlos III de Madrid, 2009, p. 813.

${ }^{51}$ Dotras, A.M., La novela española de metaficción, Madrid, Ediciones Júcar, 1994, p. 154.

${ }^{52}$ Domínguez, J. O., «El reino que será [...]», art. cit., p. 804.

${ }^{53}$ Domínguez, J. O., «El reino que será [...]», art. cit., pp. 804-805.
} 
construcción del tiempo y a la del espacio» ${ }^{54}$.

\section{BibliografíA}

BeCERra, C., Guardo la voz, cedo la palabra, Barcelona, Editorial Anthropos, 1990.

CAPEL, H., «Percepción del medio y comportamiento geográfico», Revista de Geografía, 7/1-2 (1973), pp. 58-150.

Carré Alvarellos, L., Las leyendas tradicionales gallegas, Madrid, Espasa-Calpe, 2004.

Claval, P., «Mitos e imaginarios en geografía», en A. Lindón y D. Hiernaux (dirs.), Geografias de lo imaginario, Barcelona, Anthropos, 2012, pp. 29-48.

Domínguez, J. O., «El reino que será (o de cómo la fantasía recreó al mundo)», en T. López Pellisa y Á. Moreno Serrano (eds.), Ensayos sobre ciencia ficción y literatura fantástica, Madrid, Asociación Cultural Xatafi y Universidad Carlos III de Madrid, 2009, pp. 804-814.

Hutcheon, L., Narcissistic Narrative. The Metafictional Paradox, New York, Methuen, 1984.

Loureiro, Á., «Torrente Ballester, novelista postmoderno», en Á. Abuín, C. Becerra y M. Candelas (eds.), La creación literaria de Gonzalo Torrente Ballester, Vigo, Tambre crítica, 1997, pp. 60-76.

MalaxecheVerria, I., Bestiario medieval, Madrid, Siruela, 1999.

MAriÑo Ferro, X. R., «A coca e o dragón: Introducción á zooloxía fantástica», en Actas do I Congreso Internacional da Cultura Galega, Santiago de Compostela, Dirección Xeral de Cultura, 1992, pp. 289-303.

NAGEL, F., «Galicia en movimiento. Topologías mitográficas en la narrativa de Gonzalo Torrente Ballester», en C. Rivero Iglesias (ed.), El realismo en Gonzalo Torrente Ballester: poder, religión y mito, Madrid, Iberoamericana, 2013, pp. 275-288.

PÉrez, J., «La función desmitificadora de los mitos en la obra literaria de Gonzalo Torrente Ballester», Actas del octavo Congreso de la Asociación Internacional de Hispanistas: celebrado en Brown University, Providence Rhode Island, del 22 al 27 de agosto de 1983, Volumen II, Madrid, Ediciones Istmo, 1986, pp. 437-446.

Querol, J. M., «Imago mundi: la construcción literaria de la geografía mítica, fantástica y política», en T. López Pellisa y Á. Moreno Serrano (eds.), Ensayos sobre ciencia ficción y literatura fantástica, Madrid, Asociación Cultural Xatafi y Universidad Carlos III de Madrid, 2009, pp. 863-877.

Rómar, A., «El mito y la ciencia ficción: polos de la explicación imaginaria de la realidad», en T. López Pellisa y Á. Moreno Serrano (eds.), Ensayos sobre ciencia

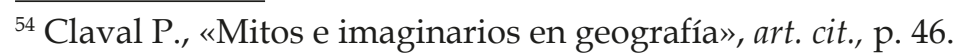

